\title{
Infusing Critical Conversations about Cultural Awareness, Identity, and Mental Health into a Research-Intensive Program for Hispanic/Latinx Undergraduates in STEM
}

\author{
Aimee Hernandez, Karina C. Canaba, Laura A. Diaz-Martinez, and Jeffrey \\ T. Olimpo
}

The University of Texas at El Paso, Biological Sciences, 500 W. University Ave, B226 Biology

Bldg, El Paso TX 79968 USA

(aahernandez18@miners.utep.edu)

\begin{abstract}
Growing concern exists about the prevalence of mental illness in graduate education, which has been associated with a lack of mentorship from graduate students' advisors combined with significant levels of fiscal and emotional stress commonly associated with the pursuit of a graduate degree. This prevalence is often further exacerbated in minoritized graduate student populations due to the constructs of racism, sexism, and microaggressions in academic contexts. In response to this concern, we offered a four-part Critical Conversations workshop aimed at undergraduate students $(n=17)$ in the ACSScellence program at our institution, a research-intensive experience designed to prepare Hispanic/Latinx students for graduate studies in STEM. Specifically, through an interactive journal club, we discussed the importance of: (1) cultural awareness; (2) the advisor selection process; (3) identity-constructs and mental health; and (4) how to deal with microaggressions in academia. Data obtained from student responses to one-minute paper prompts and open-ended questionnaires were used to evaluate the impact of the intervention. Content analyses indicated that students ( $76 \%$ or more per category) developed an increased awareness of what constitutes a healthy mentoring relationship, strategies to maintain work-life balance in research positions, and socio-cultural competence as a result of participating in the workshop.
\end{abstract}

Keywords: Hispanic/Latinx student mentorship, Critical Conversations, ACSScellence program, cultural awareness

\section{Mission, Review Process \& Disclaimer}

The Association for Biology Laboratory Education (ABLE) was founded in 1979 to promote information exchange among university and college educators actively concerned with teaching biology in a laboratory setting. The focus of ABLE is to improve the undergraduate biology laboratory experience by promoting the development and dissemination of interesting, innovative, and reliable laboratory exercises. For more information about ABLE, please visit http://www.ableweb.org/.

Advances in Biology Laboratory Education is the peer-reviewed publication of the conference of the Association for Biology Laboratory Education. Published articles and extended abstracts are evaluated and selected by a committee prior to presentation at the conference, peer-reviewed by participants at the conference, and edited by members of the ABLE Editorial Board. Published abstracts are evaluated and selected by a committee prior to presentation at the conference.

\section{Citing This Article}

Hernandez A, Canaba KC, Diaz-Martinez LA, Olimpo JT. 2020. Infusing critical conversations about cultural awareness, identity, and mental health into a research-intensive program for Hispanic/Latinx undergraduates in STEM. Article 71 In: McMahon K, editor. Advances in biology laboratory education. Volume 41. Publication of the 41st Conference of the Association for Biology Laboratory Education (ABLE). https://doi.org/10.37590/able.v41.abs71 
Compilation (C) 2020 by the Association for Biology Laboratory Education, ISBN 1-890444-17-0. All rights reserved. Nopart of this publication may be reproduced, stored in a retrieval system, or transmitted, in any form or by any means, electronic, mechanical, photocopying, recording, or otherwise, without the prior written permission of the copyright owner.

ABLE strongly encourages individuals to use the exercises in this volume in their teaching program. If this exercise is used solely at one's own institution with no intent for profit, it is excluded from the preceding copyright restriction, unless otherwise noted on the copyright notice of the individual chapter in this volume. Proper credit to this publication must be included in your laboratory outline for each use; a sample citation is given above. 